\title{
Innovation \& Market Consolidation Among Electronic Health Record Vendors: An Acute Need for Regulation
}

\author{
J. Wanderer • P. Mishra $・$ J. Ehrenfeld
}

Published online: 15 January 2014

(C) Springer Science+Business Media New York 2014

\section{Introduction}

Each week, electronic health records (EHRs) become more ubiquitous and an increasingly important part of our nation's $\$ 2.7$ trillion health economy [1]. While the promises of increased efficiency, cross facility interoperability, and point-ofcare benefits have been modestly fulfilled [2,3], it is clear that adoption of EHRs will only increase for the foreseeable future. However, tremendous market consolidation has resulted in a small number of programs obtaining a large share of installed systems. This effective monopoly by a group of vendors has stifled innovation and made disruptive innovation very difficult. In order to combat this problem, EHR vendors should be required to open systems up to allow for more clinical innovation.

Adoption of EHRs is being driven by a multitude of factors. In February 2009, President Obama signed into law the American Recovery and Reinvestment Act (AARA), a \$789 billion economic stimulus package, which includes the Healthcare Information Technology for Economic and Clinical Health Act (HITECH Act). The HITECH Act is designed to encourage investment in health information technology so that both healthcare delivery and patient care can be improved. As a consequence of the HITECH Act, which allocates \$25.9 billion to hospitals and physicians who demonstrate meaningful use of electronic health records, many hospitals have adopted digitalized technology. Eligible providers are now

J. Ehrenfeld $(\bowtie)$

Vanderbilt University Medical Center, 1301 Medical Center Drive, 4648 The Vanderbilt Clinic, Nashville, TN 37232, USA

e-mail: jesse.ehrenfeld@vanderbilt.edu

J. Wanderer $\cdot$ P. Mishra

Department of Anesthesiology, Vanderbilt University, Nashville, USA able to obtain up to $\$ 63,750$ in payments from the government for demonstration of the use of certified systems [4].

Additionally, pay-for-performance contracting with private insurers has spurred many physicians and hospitals to adopt EHRs in order to be able to participate in these programs [5]. The increasing need for external data reporting, such as statebased reporting programs, along with a general desire to utilize technology to facilitate quality improvement have also helped drive adoption [6]. EHR system use among officebased physicians increased from $18 \%$ in 2001 to $57 \%$ in preliminary 2011 estimates [7].

As the number of physician practices using EHRs increases, there has been a simultaneous decline in the variety of systems installed. Market consolidation has steadily increased, as evidenced by data now available from CMS. Although several hundred unique EHR systems have been certified for use by CMS, according to CMS attestation data, 15 vendors represented $75 \%$ of the systems among all providers attesting to meaningful use. Among inpatient EHRs, this consolidation is even more pronounced with just 6 vendors representing $75 \%$ of all hospital attestations [8].

\section{AIMS market}

The anesthesiology information management system (AIMS) market is a telling example of the larger national EHR trends. AIMS are a specialized form of EHR used by anesthesiologists to monitor and record perioperative patient data $[9,10]$. Since 2009, there has been a steady increase in AIMS adoption. In 2009, less than $5 \%$ of US operating rooms were using AIMS. By 2011, $50 \%$ of operating rooms were using AIMS according to survey data. In the AIMS market, there are only four major health information technology companies offering systems: Picis, Draeger Medical, Philips, and GE. Although there are a handful of other companies, these four control the 
vast majority of the AIMS market and are estimated to represent approximately $75 \%$ of all installed AIMS systems [11]. With these companies having a stronghold on the market, it is becoming increasingly difficult for other companies to enter the AIMS market, thus stifling both competition and creativity.

Market consolidation does not necessarily obviate innovation. One only has to look at the electrical power industry to see an example of how combinations of standards and regulations have allowed innovation to occur in concert with a small number of broadly entrenched service providers. While the nation's electrical power generation and transmission system is complex and dominated by a few large players, there are many small companies that have leveraged national standards to innovate within the marketplace. A growing number of renewable energy companies, wind and solar in particular, have been able to bring their products to market by connecting to one of the three national grids that serve as a marketplace for electrical power. The existing infrastructure essentially became a platform for energy innovation. By analogy, EHR systems could be regulated to function as open, flexible platforms that allow innovative use of EHR data by other vendors to drive clinical innovation. Another example similar to electrical power is the smartphone application industry. The iOS and Android systems have become platforms that provide common interfaces to core functionality, such as global positioning systems, cameras and address books, for any application. Users can choose from multiple competing applications for a specific task or create their own. This platform approach has fostered a revolution in software application development and led to a numerous innovations.

While a similarly innovative platform does not yet exist in the EHR space, ongoing research and development efforts have demonstrated that it is possible to apply the same approach to EHR systems. Through a grant from the Office of the National Coordinator for Health Information Technology, the Substitutable Medical Applications, Reusable Technology (SMART) Platforms project has developed applications and interfaces that provide a common way to work with existing health data [12]. By using existing web standards (HTML, JavaScript) and medical coding standards (SNOMED, RxNorm), the SMART team has developed an open framework that allowed outside software developers to write novel applications that interface with proprietary EHR systems. Applications interface with normalized clinical data through SMART containers, which obviate the need to adapt functionality for a particular vendor system. Currently, there is limited ability for individuals, small companies, or others to develop and innovate within and around large vendor installed systems. If regulatory standards that govern which EHR systems are certified for government incentive programs included interoperability features demonstrated by the SMART team, the marketplace would see many innovative healthcare applications be developed.

\section{Non-commercial systems}

At Vanderbilt University Medical Center (VUMC), we have developed an in-house EHR system which includes innovative AIMS applications. Anesthesiologists frequently supervise multiple concurrent surgical cases, which makes it challenging to determine what is occurring in each case in realtime and prioritize appropriately. We have created an iPhone application called VigiVU (Fig. 1) that allows anesthesiologists to watch and control operating room cameras, monitor vital sign trends, and communicate directly with staff in each room [13]. This innovation has dramatically changed the way in which our physicians are able to do their jobs. Our development team was able to create this application because they had full access to our EHR system which contains the underlying data. Bringing this innovation to operating rooms outside VUMC, however, remains challenging because EHR systems lack the interoperability features required for accessing patient data in real-time. This is functionality that is needed and has already been developed in our AIMS; yet the current structure of the EHR marketplace greatly constrains our ability to spread this innovation. Similarly, we have demonstrated how additional functionality can be created on top of existing AIMS to improve compliance documentation $[14,15]$, streamline a quality assurance system [16], and improve monitoring of patients $[17,18]$. While some of these important innovations have been subsequently implemented elsewhere [19], doing so required creating a new software system from scratch. Only a handful of other medical centers have invested the resources needed to develop novel functionality [20-22] and instead most rely on vendor driven updates. This is problematic for fields like anesthesiology, where the size of the market is relatively small, and vendor updates are typically incremental rather than pioneering.

\section{Regulation as a facilitator for industry change}

Industries respond to the regulatory environment in a predictable fashion, and therefore the regulatory environment can serve as a facilitator for change. In 2002, the White Dog Café became the first for-profit business in Philadelphia to use $100 \%$ wind-generated electricity [23]. The café does not produce or generate any energy itself - green or otherwise; rather it was able to purchase "green" power from generation suppliers outside the city which it received via the existing energy grid. This would not have been possible without an energy regulatory structure which has established a market where the ability to purchase renewable energy credits, 
Fig. 1 The VigiVu iPhone application allows supervising physicians to simultaneously monitor four operating rooms by observing live video and real-time vitals signs

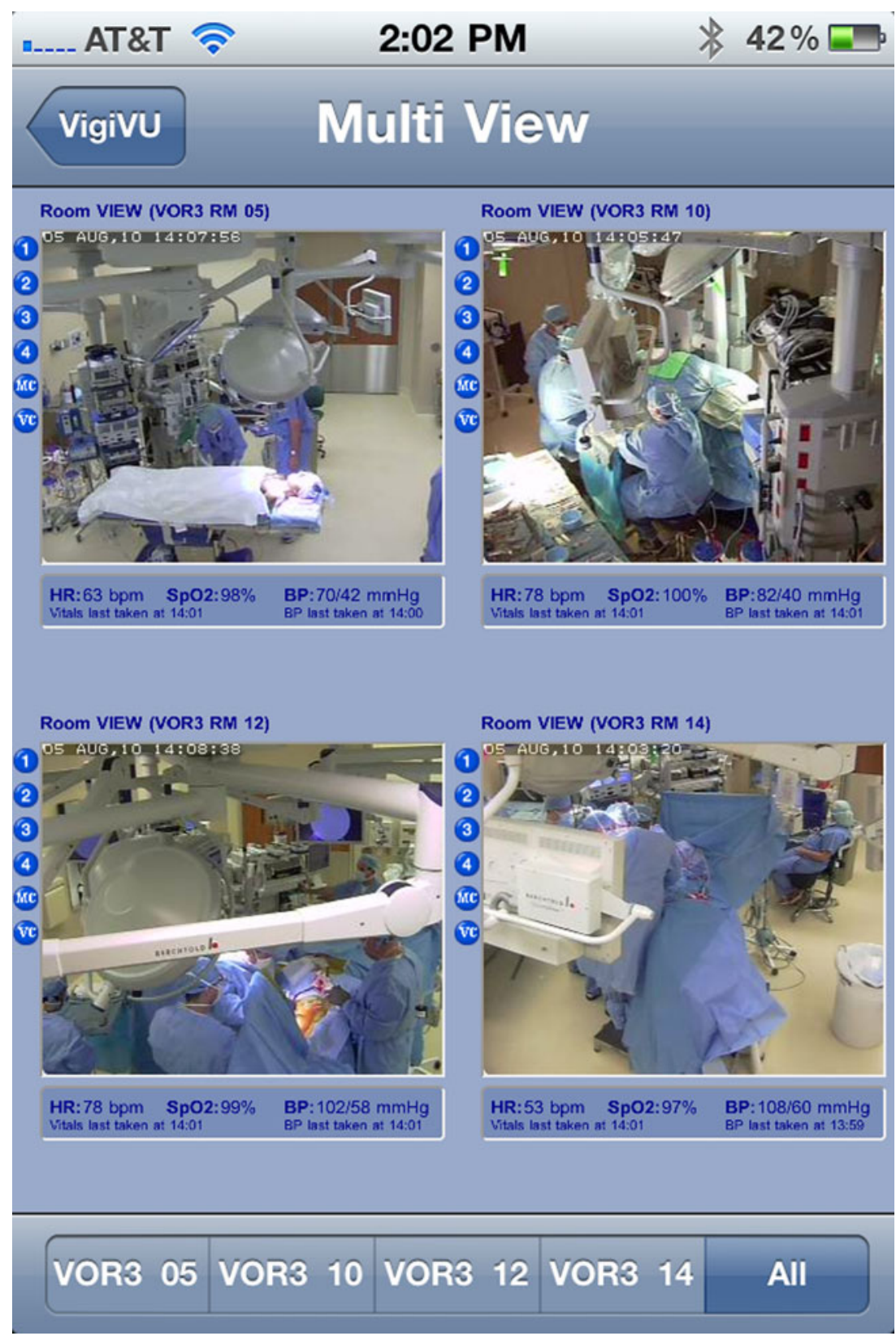

certified green energy sources, and track green energy usage exists. Thus the café can participate in enhancing national energy innovation without building its own independent power grid or generation facility. In contrast, if another institution wanted to use VigiVU, it would have to perform the equivalent of digging holes for new utility poles, hanging highvoltage wire or running its own generation infrastructure. Within the community of clinicians and software developers that use and support AIMS applications, there is a clear need for interoperability, access to normalized real-time patient data, and the ability to share novel functionality across multiple vendor systems. These practical needs also exist within the broader EHR community, and these abilities would greatly improve the potential for health information technology to achieve its goals of improving healthcare delivery and patient care. The remaining question is how to establish the innovative platform approach using existing EHR systems.

\section{Sustaining innovation}

Disruptive innovations are frequently discussed in the context of healthcare and are described as innovations that create a new market which eventually disrupts an existing market by displacing older technology $[24,25]$. We envision, by contrast, sustaining innovation, whereby existing markets evolve to allow competition between firms that create better value $[26,27]$. Billions of dollars have already been spent creating 
interfaces to legacy hardware and data for current EHR systems, and it would be wiser to build on top of what we have rather than seek to replace these systems. The HITECH Act has already essentially established a mechanism for regulating necessary EHR system functionality through the EHR certification process. This same process could be leveraged to encourage EHR vendors to adopt the practical interoperability approach demonstrated by the SMART team. A change such as this would have a powerful impact.

\section{Conclusions}

While our VigiVU application is currently limited to VUMC, the regulatory change we suggest could alter this completely. By allowing access to normalized clinical data in current systems through SMART containers, innovative applications could be brought across institutional boundaries. Just as the iOS and Android systems have published interfaces to core features such as cameras and address books, AIMS could have an interface to common parameters found in anesthetic care records. By combining these data with an EHR provider address book interface and a camera interface, VigiVU and other novel applications could be shared far beyond the walls of VUMC, and anesthesiologists across the nation could have access to this innovation without having to reinvent the wheel at each institution. By permitting access to normalized realtime patient data, clinicians, researchers, and developers will be able to fully leverage vendor EHRs. The resulting clinical innovations will be critical in improving our nation's healthcare delivery and in achieving health information technology's potential to improve patient care.

\section{References}

1. Centers for Medicare and Medicaid Services. National Health Expenditure Projections 2011-2021 2011. http://www.cms.gov/ Research-Statistics-Data-and-Systems/Statistics-Trends-andReports/NationalHealthExpendData/Downloads/Proj2011PDF.pdf (accessed 27 December 2012).

2. Uslu, A. M., and Stausberg, J., Value of the electronic patient record: An analysis of the literature. J. Biomed. Inform. 41:675-682, 2008.

3. Kadry, B., Sanderson, I. C., and Macario, A., Challenges that limit meaningful use of health information technology. Curr. Opin. Anaesthesiol. 23:184-192, 2010.

4. Department of Health and Human Services, Health information technology: Initial set of standards, implementation specifications, and certification criteria for electronic health record technology. Final rule. Fed. Regist. 75:44589-44654, 2010.

5. Robinson, J. C., Casalino, L. P., Gillies, R. R., et al., Financial incentives, quality improvement programs, and the adoption of clinical information technology. Med. Care 47:411-417, 2009.

6. Casalino, L., Gillies, R. R., Shortell, S. M., et al., External incentives, information technology, and organized processes to improve health care quality for patients with chronic diseases. JAMA 289:434-441, 2003.

7. Hsiao, C. J., Hing, E., Socey, T. C., et al. Electronic health record systems and intent to apply for meaningful use incentives among office-based physician practices: United States, 2001-2011. NCHS data brief :1-8, 2011 .

8. Department of Health and Human Services. CMS Medicare and Medicaid EHR Incentive Program, electronic health record products used for attestation 2012. http://www.data.gov (accessed 27 December 2012).

9. Kadry, B., Feaster, W. W., Macario, A., et al., Anesthesia information management systems: Past, present, and future of anesthesia records. Mt Sinai J. Med. 79:154-165, 2012.

10. Ehrenfeld, J. M., and Rehman, M. A., Anesthesia information management systems: A review of functionality and installation considerations. J. Clin. Monit. Comput. 25:71-79, 2011.

11. Stonemetz, J., Anesthesia information management systems marketplace and current vendors. Anesthesiol. Clin. 29:367375, 2011.

12. Mandl, K. D., Mandel, J. C., Murphy, S. N., et al., The SMART Platform: Early experience enabling substitutable applications for electronic health records. J. Am. Med. Inform. Assoc. 19:597-603, 2012.

13. Lane, J. S., Sandberg, W. S., and Rothman, B., Development and implementation of an integrated mobile situational awareness iPhone application VigiVU at an academic medical center. Int. J. Comput. Assist. Radiol. Surg. 7:721-735, 2012.

14. Spring, S. F., Sandberg, W. S., Anupama, S., et al., Automated documentation error detection and notification improves anesthesia billing performance. Anesthesiology 106:157-163, 2007.

15. Sandberg, W. S., Sandberg, E. H., Seim, A. R., et al., Realtime checking of electronic anesthesia records for documentation errors and automatically text messaging clinicians improves quality of documentation. Anesth. Analg. 106:192201, 2008.

16. Peterfreund, R. A., Driscoll, W. D., Walsh, J. L., et al., Evaluation of a mandatory quality assurance data capture in anesthesia: a secure electronic system to capture quality assurance information linked to an automated anesthesia record. Anesth. Analg. 112:1218-1225, 2011.

17. Ehrenfeld, J. M., Epstein, R. H., Bader, S., et al., Automatic notifications mediated by anesthesia information management systems reduce the frequency of prolonged gaps in blood pressure documentation. Anesth. Analg. 113:356-363, 2011.

18. Chau, A., and Ehrenfeld, J. M., Using real-time clinical decision support to improve performance on perioperative quality and process measures. Anesthesiol. Clin. 29:57-69, 2011.

19. Nair, B. G., Newman, S. F., Peterson, G. N., et al., Smart anesthesia manager (TM) (SAM)-A real-time decision support system for anesthesia care during surgery. IEEE Trans. Biomed. Eng. 60:207-210, 2013.

20. Bicker, A. A., Gage, J. S., and Poppers, P. J., An evolutionary solution to anesthesia automated record keeping. J. Clin. Monit. Comput. 14:421-424, 1998.

21. Abenstein, J. P., De Vos, C. B., Abel, M. D., et al., Eight year's experience with automated anesthesia record keeping: Lessons learned-new directions taken. Int. J. Clin. Monit. Comput. 9:117129, 1992.

22. Merry, A. F., Webster, C. S., and Mathew, D. J., A new, safety-oriented, integrated drug administration and automated anesthesia record system. Anesth. Analg. 93:385-390, 2001.

23. U.S. Department of Energy. White Dog Cafe Receives Wind Powering America Award For 100\% Wind Energy Usage 2002. http://www.windpoweringamerica.gov/pdfs/wpa/whitedogcafe.pdf (accessed 27 December 2012). 
24. Christensen, C. M., The innovator's dilemma: When new technologies cause great firms to fail, vol. xxiv. Harvard Business School Press, Boston, p. 252, 1997.

25. Sandberg, W. S., Barbarians at the gate. Anesth. Analg. 109:695-699, 2009.
26. Danneels, E., Disruptive technology reconsidered: A critique and research agenda. J. Prod. Innov. Manag. 21:246-258, 2004.

27. Danneels, E., Dialogue on the effects of disruptive technology on firms and industries. J. Prod. Innov. Manag. 23:2-4, 2006. 